Research Paper

\title{
Cervical Dilatation Curves of Spontaneous Deliveries in Pregnant Japanese Females
}

\author{
Yusuke Inde ${ }^{1}$, Akihito Nakai ${ }^{1}{ }^{凶}$, Atsuko Sekiguchi ${ }^{1}$, Masako Hayashi ${ }^{1}$, Toshiyuki Takeshita ${ }^{2}$ \\ 1. Department of Obstetrics and Gynecology, Nippon Medical School Tama-Nagayama Hospital, Tokyo, Japan \\ 2. Department of Obstetrics and Gynecology, Nippon Medical School, Tokyo, Japan \\ $\triangle$ Corresponding author: Prof. Akihito Nakai, Department of Obstetrics and Gynecology, Nippon Medical School Tama-Nagayama Hospital, 1-7-1 Nagayama, \\ Tama, Tokyo 206-8512, Japan. E-mail: nakai-3@nms.ac.jp, TEL: +81-42-371-2111, FAX: +81-42-372-7372 \\ (C) Ivyspring International Publisher. This is an open access article distributed under the terms of the Creative Commons Attribution (CC BY-NC) license \\ (https://creativecommons.org/licenses/by-nc/4.0/). See http://ivyspring.com/terms for full terms and conditions.
}

Received: 2017.10.26; Accepted: 2018.02.07; Published: 2018.03.09

\begin{abstract}
Background: Although cervical dilatation curves are crucial for appropriate management of labor progression, abnormal labor progression and obstetric interventions were included in previous and widely-used cervical dilatation curves. We aimed to describe the cervical dilatation curves of normal labor progression in pregnant Japanese females without abnormal labor progression and obstetric interventions.

Methods: We completed retrospective obstetric record reviews on 3172 pregnant Japanese females ( arity $=0, n=1047$; parity $=1, n=1083$; parity $\geq 2, n=1042$ ), aged 20 to 39 years old at delivery, with pregravid body mass indices of less than 30 . All patients underwent spontaneous deliveries with term, singleton, cephalic and live newborns of appropriate-for-gestational age birthweight, without adverse neonatal outcomes. We characterized labor progression patterns by examining the relationship between elapsed times from the full dilatation and cervical dilatation stages, and labor durations by examining the distribution of time intervals from one cervical dilatation stage, to the next, and ultimately to the full dilatation.

Results: Fastest cervical changes occurred at $6 \mathrm{~cm}$ (primiparas) and $5 \mathrm{~cm}$ (multiparas) of dilatation. The $95 \%$ tile of labor progression took over 3 hours to progress from $6 \mathrm{~cm}$ to $7 \mathrm{~cm}$ (primiparas), and over 2 hours to progress from $5 \mathrm{~cm}$ to $6 \mathrm{~cm}$ (multiparas). The $5 \%$ tile of traverse time to the full dilatation, during the active phase, was less than 1 hour (primiparas) and 0.5 hours (multiparas). At the end of the active phase, no deceleration phase was observed.

Conclusions: Active labor may not start until $5 \mathrm{~cm}$ of dilatation. At the beginning of the active phase, cervical dilatation was slower than previously described. These results may reduce opportunities for obstetric interventions during labor progression.
\end{abstract}

Key words: cervical dilatation, first stage of labor, labor curve, labor management, spontaneous delivery

\section{Introduction}

Cervical dilatation curves serve as clinical reference for appropriate management of labor progression. Inaccurate diagnosis of protracted or arrested labor may lead to inappropriate obstetric interventions including cesarean section (CS) deliveries. Considering risks associated with primary CS and adverse CS-related implications for subsequent pregnancies, primary CS should be avoided if possible [1]. Friedman was the first to depict the preliminary labor curve [2], and two landmark labor curves of primiparas and multiparas which showed definite criteria for labor progression and duration [3, 4]. However, abnormal labor progression and obstetric interventions were included in these previous, widely-used cervical dilatation curves.

Past theories on labor progression and duration may no longer be applicable to those in current obstetric practice [5]. Friedman established mean labor curves that considered various exogenous, and endogenous, maternal and fetal factors. Besides changes in maternal and fetal characteristics, obstetric interventions and statistical procedures have impro- 
ved $[3,4]$. Recent labor curves by Zhang et al. and Suzuki et al. markedly differ from Friedman's labor curves, featuring slower cervical dilatation in the acceleration phase and lack of the deceleration phase $[6,7]$. Their study designs also included variations in maternal and fetal backgrounds, and included abnormal labor progression and obstetric interventions.

Establishment of referential labor curves for spontaneous deliveries is necessary for appropriate management of labor progression. Various factors which may affect labor progression and duration included maternal race and age [8], maternal and fetal body sizes [9], gestational age at delivery [10], twin gestations [11], obstetric anesthesia [12], oxytocin use $[3,4]$, obstetric complications [3, 4], and complicated pregnancies [13]. Obstetric anesthesia and oxytocin use are often considered as optional obstetric interventions during spontaneous deliveries [3-13]. To develop referential labor curves for normal labor progression and duration, we describe spontaneous cervical dilatation curves, based on standard maternal and fetal populations.

\section{Materials and Methods}

We retrospectively reviewed 3172 obstetric records of 1047 primiparous and 2125 multiparous (1083 of parity $=1$ and 1042 of parity $\geq 2$ ) pregnant Japanese females. All patients had spontaneous deliveries with live newborns of appropriate-forgestational age (AGA) birthweight between January 2008 and December 2015. Maternal characteristics and perinatal outcomes were obtained from six primary obstetric institutions [Berun Forest Clinic $(\mathrm{N}=759)$, Belier Hill Clinic $(\mathrm{N}=413)$, Ladies Clinic Concerto ( $\mathrm{N}$ $=$ 153), Machida Obstetrics and Gynecology Nanohana Clinic ( $\mathrm{N}=56)$, Higashi-Fuchu Hospital ( $\mathrm{N}$ $=128)$ and Yamaguchi Women's Hospital $(\mathrm{N}=343)]$ and one university hospital [Nippon Medical School Tama-Nagayama Hospital $(\mathrm{N}=1320)]$. All sites agreed to participate in this study. The ethics committee of Nippon Medical School approved this retrospective study, which conformed to the principles established by the Declaration of Helsinki. We extracted continuous time-stamped cervical dilatation measurements, after onset of labor, from labor charts. A single researcher posted obstetric records from parturition ledgers and a trained researcher checked for posting errors. All researchers maintained anonymity of all participants.

Exclusion criteria included: non-Japanese, multiple pregnancies, maternal age less than 20, or 40 and over at delivery, pregravid body mass index (BMI) 30 and over, prior CS delivery, prior enucleatic myomectomy, preterm or post-term delivery, malpresentation, instrumental or CS delivery, malrotation, obstetric anesthesia, oxytocin use, cephalopelvic disproportion, placental abruption, non-AGA birthweight, congenital anomaly, birth injury, 5-minute Apgar scores lower than 7, neonatal intensive care unit (NICU) admission, and perinatal death. To investigate the natural history of spontaneous labor progression, we established no exclusion criteria for cervical dilatation at admission or labor duration from admission to delivery. Among the multiparas, we selected the first delivery to avoid intrapersonal correlation.

Clinical definitions were as follows: Gestational age was determined from the first day of the patient's last menstrual period, and reconfirmed with fetal crown-rump length, measured by transvaginal ultrasound in the first trimester. Fetal presentation was assessed before and at admission by transabdominal ultrasound. Onset of labor was defined as onset of labor pains, which continued to delivery, with $\leq 10$ minutes interval between contractions, or $\geq 6$ times the number of contractions per hour. Midwives and obstetricians performed cervical dilatation measurements in centimeters, commonly at onset of labor pain, not during intervals between labor pains, as directed by institution care standards or guided by obstetric events such as admission, rupture of the membranes, intensive constructions, fetal heart rate pattern changes, breathing changes, or spontaneous pushing. However, we could not completely clarify whether all pelvic examinations were taken at onset of labor pain. Non-pharmacological approaches (e.g., nipple stimulation, castor oil and herbs) were not conducted. Episiotomy required maternal or fetal indications. There was no major difference in the management of labor among the study centers and during the study period.

We analyzed the normality of continuous variables using the Shapiro-Wilk W-test. Medians and 95\% confidence intervals were calculated for non-normally distributed continuous variables. Statistical differences in maternal characteristics and perinatal outcomes between primiparas and multiparas (parity $=1$ and $\geq 2$ ) were analyzed using the Mann-Whitney U-test or Kruskal-Wallis test for non-normally distributed continuous variables and the $\chi^{2}$ test for categorical variables. Differences of $\mathrm{P}<$ 0.05 were considered significant. We used the JMP ${ }^{\circledR}$ 12.0 software (SAS Institute Japan Co., Ltd, Tokyo, Japan) for statistical analyses.

Major statistical analyses were conducted as previously reported [6,7]. We characterized labor progression patterns by examining the relationship between elapsed times from the full dilatation and cervical dilatation stages. Because participants were admitted at various cervical dilatation stages, which ultimately reached $10 \mathrm{~cm}$, we performed reverse 
regression analyses, with $10 \mathrm{~cm}$ of dilatation as the starting point and moving backward in time. Repeated measures regressions with sixth-degree polynomial models fit the cervical dilatation values best. We characterized labor durations by examining the distribution of time intervals from one cervical dilatation stage, to the next, and ultimately to the full dilatation. Labor durations have skewed distributions that lean left, resembling log-normal distributions. Every participant contributed interval-censored values at given cervical dilatation stages. We calculated the time interval series, between those two cervical dilatation stages for each participant.

\section{Results}

Table 1 and Table 2 show maternal characteristics and perinatal outcomes of the primiparas and multiparas. Maternal age at delivery and body mass increased with increasing parity. Premature rupture of the membranes was associated with primiparas. Labor durations decreased with increasing parity [median (95\%tile) 7.75 (18.71) vs. 4.07 (10.07) vs. 3.75 (9.91) hours at the first stage and $0.72(2.34)$ vs. 0.20
(0.75) vs. $0.15(0.55)$ hours at the second stage for parity $=0,1$ and $\geq 2$ ]. Median cervical dilatations at admission were $4 \mathrm{~cm}$ (primiparas) and $5 \mathrm{~cm}$ (multiparas). Neonatal body size increased with increasing parity. Although several newborns showed low umbilical artery $\mathrm{pH}$ and low Apgar scores at 1-minute, no newborns were admitted to NICU and no adverse neonatal outcomes were observed.

Figure 1 and Figure 2 describe averaged cervical dilatation curves for the primiparas and multiparas. The primiparous labor curve shows slow cervical dilatation during the acceleration phase with no definite inflection point, whereas the multiparous labor curves appear to accelerate around $5 \mathrm{~cm}$ of dilatation. Labor progresses faster with increasing parity, and in the multiparous labor curves, the active phase begins earlier in parity $\geq 2$, compared to parity $=1$. At the end of the active phase, we observe no deceleration phase. As multiparas were admitted at more advanced cervical dilatation stages than primiparas, the median records of most multiparas had less information on cervical dilatation measurements prior to $4 \mathrm{~cm}$.

Table 1. Maternal characteristics of primiparous and multiparous females.

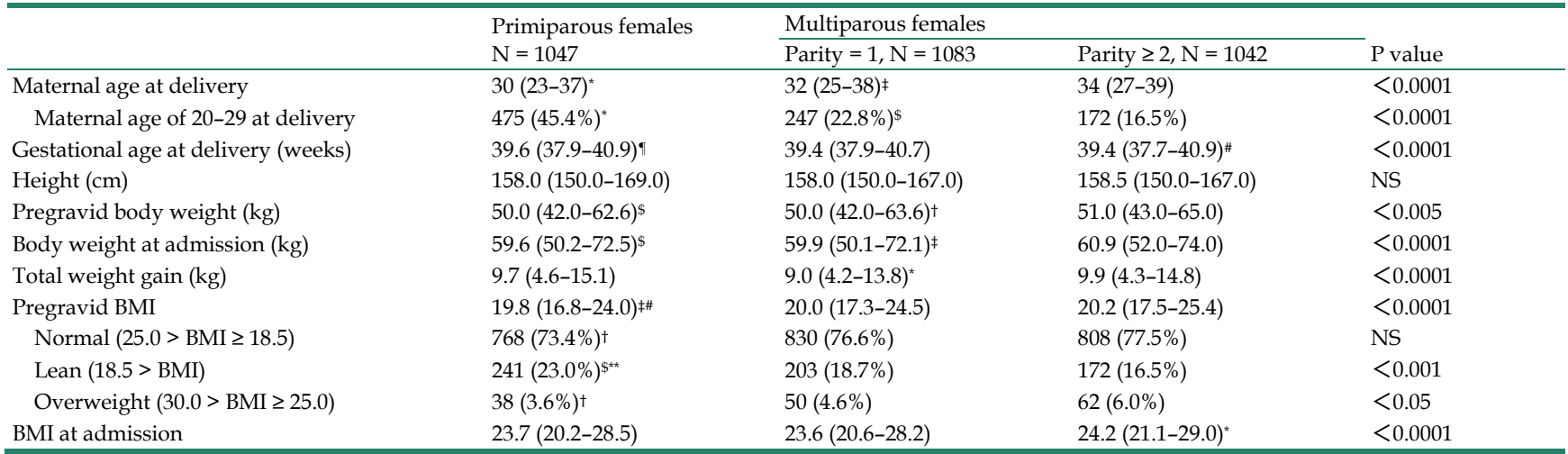

BMI, body mass index; NS, not significant

Categorical variables are shown as number of patients (\%), and numerical variables are shown as median (5\%tile-95\%tile).

${ }^{*} \mathrm{P}<0.0001$, in relation to all other groups; $\neq \mathrm{P}<0.0001$, in relation to multiparous females (parity $\geq 2$ ); $\$ \mathrm{P}<0.0005$, in relation to multiparous females (parity $\geq 2$ ); ${ }^{\mathrm{\rho}} \mathrm{P}<0.0001$, in relation to multiparous females (parity $=1$ ); $\# \mathrm{P}<0.005$, in relation to multiparous women (parity $=1$ ); $\mathrm{P}<<0.05$, in relation to multiparous females (parity $\geq 2$ ); ${ }^{* \star} \mathrm{P}<0.05$, in relation to multiparous females (parity $=1$ )

Table 2. Perinatal outcomes of primiparous and multiparous females.

\begin{tabular}{|c|c|c|c|c|}
\hline & \multirow{2}{*}{$\begin{array}{l}\text { Primiparous females } \\
\mathrm{N}=1047\end{array}$} & \multicolumn{2}{|l|}{ Multiparous females } & \multirow[b]{2}{*}{$P$ value } \\
\hline & & Parity $=1, N=1083$ & Parity $\geq 2, N=1042$ & \\
\hline Premature rupture of the membranes & $282(26.9 \%)^{\ddagger}$ & $164(15.1 \%)$ & $179(17.2 \%)$ & $<0.0001$ \\
\hline Total labor durations (hr) ${ }^{*}$ & $8.48(3.10-19.98)^{\ddagger}$ & $4.37(1.47-10.43)^{\$}$ & $3.97(1.27-10.12)$ & $<0.0001$ \\
\hline Labor durations at the first stage (hr) & $7.75(2.43-18.71)^{\ddagger}$ & $4.07(1.24-10.07)$ ฯ & $3.75(1.05-9.91)$ & $<0.0001$ \\
\hline Labor durations at the second stage (hr) & $0.72(0.17-2.34)^{\ddagger}$ & $0.20(0.03-0.75)^{\#}$ & $0.15(0.03-0.55)$ & $<0.0001$ \\
\hline Total labor durations $<3 \mathrm{hr}$ & $46(4.4 \%)^{\ddagger}$ & $294(27.1 \%)^{\dagger}$ & $335(32.1 \%)$ & $<0.0001$ \\
\hline Times of vaginal examinations & $6(3-10)^{\ddagger}$ & $4(3-8)^{\#}$ & $5(3-8)$ & $<0.0001$ \\
\hline Cervical dilatation stage at admission $(\mathrm{cm})$ & $4(2-9)^{\ddagger}$ & $5(2-9)^{\$}$ & $5(2-9)$ & $<0.0001$ \\
\hline Episiotomy & $353(33.7 \%)^{\ddagger}$ & $113(10.4 \%)^{\#}$ & $39(3.7 \%)$ & $<0.0001$ \\
\hline Total blood loss including amnion (g) & $344(114-1017)^{\ddagger}$ & $250(90-835)$ & $255(100-829)$ & $<0.0001$ \\
\hline Umbilical arterial $\mathrm{pH}$ & $7.280(7.170-7.371)^{\ddagger}$ & $7.310(7.200-7.415)^{\#}$ & $7.328(7.211-7.440)$ & $<0.0001$ \\
\hline Umbilical arterial $\mathrm{pH}<7.100$ & $10(0.9 \%)$ & $6(0.6 \%)$ & $4(0.4 \%)$ & NS \\
\hline Umbilical cord entanglement & $364(34.8 \%)^{\dagger}$ & $361(33.3 \%)$ & $318(30.5 \%)$ & NS \\
\hline Neonatal characteristics & & & & \\
\hline
\end{tabular}




\begin{tabular}{|c|c|c|c|c|}
\hline & \multirow{2}{*}{$\begin{array}{l}\text { Primiparous females } \\
\mathrm{N}=1047\end{array}$} & \multicolumn{2}{|l|}{ Multiparous females } & \multirow[b]{2}{*}{$P$ value } \\
\hline & & Parity $=1, \mathrm{~N}=1083$ & Parity $\geq 2, N=1042$ & \\
\hline Female & $508(48.5 \%)$ & $537(49.6 \%)$ & $527(50.6 \%)$ & NS \\
\hline Birthweight (g) & $2962(2443-3420)^{\ddagger}$ & $3004(2523-3520)^{\#}$ & $3080(2574-3630)$ & $<0.0001$ \\
\hline Height $(\mathrm{cm})$ & $49.0(46.0-51.5)$ & $49.0(46.0-51.5)$ & $49.5(47.0-52.0)^{\ddagger}$ & $<0.0001$ \\
\hline Head circumference $(\mathrm{cm})$ & $33.0(31.0-35.0)^{\ddagger}$ & $33.0(31.0-35.0)^{\dagger}$ & $33.5(31.5-35.0)$ & $<0.0001$ \\
\hline Apgar score at 1 minute $<7$ & $4(0.4 \%)$ & $4(0.4 \%)$ & $2(0.2 \%)$ & NS \\
\hline Apgar score at 5 minute $<7$ & $0(0.0 \%)$ & $0(0.0 \%)$ & $0(0.0 \%)$ & - \\
\hline
\end{tabular}

NS, not significant

Categorical variables are shown as number of patients (\%), and numerical variables are shown as median (5\%tile- $95 \%$ tile).

"Total labor duration consists of the labor durations at first and second stages.

$\ddagger \mathrm{P}<0.0001$, in relation to all other groups; $\$ \mathrm{P}<0.005$, in relation to multiparous females (parity $\geq 2$ ); $\uparrow \mathrm{P}<0.01$, in relation to multiparous females (parity $\geq 2$ ); $\# \mathrm{P}<0.0001$, in relation to multiparous females (parity $\geq 2$ ); $+\mathrm{P}<0.05$, in relation to multiparous females (parity $\geq 2$ )

A.

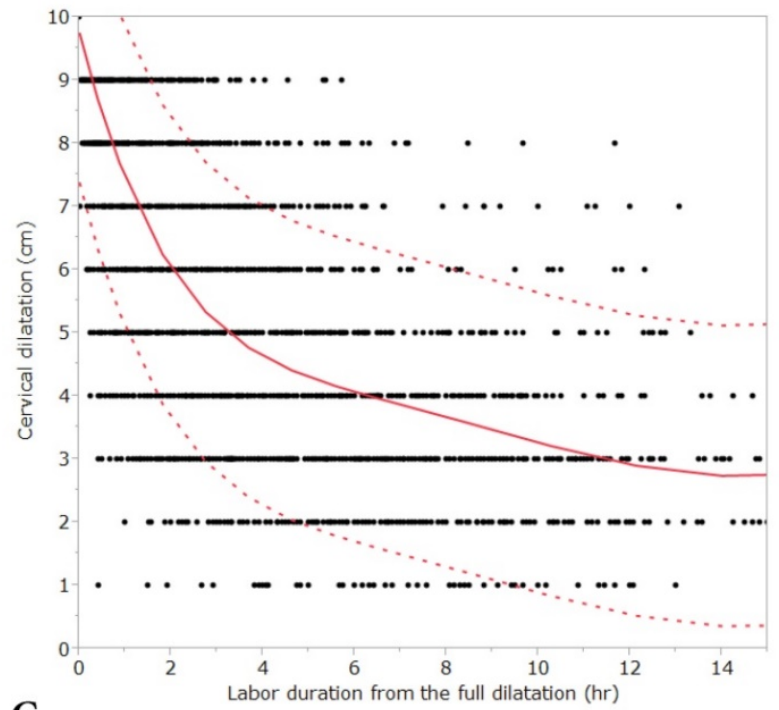

C.

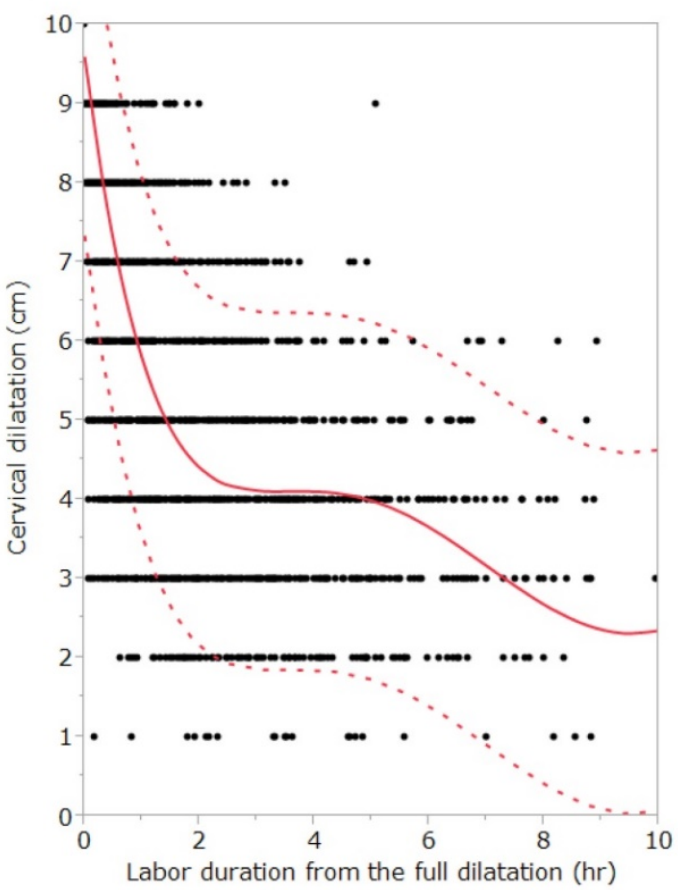

B.

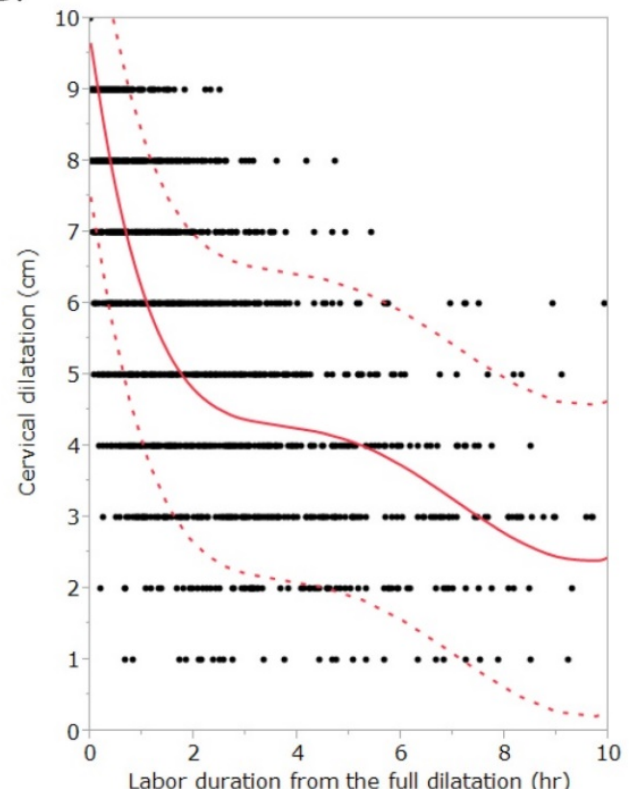




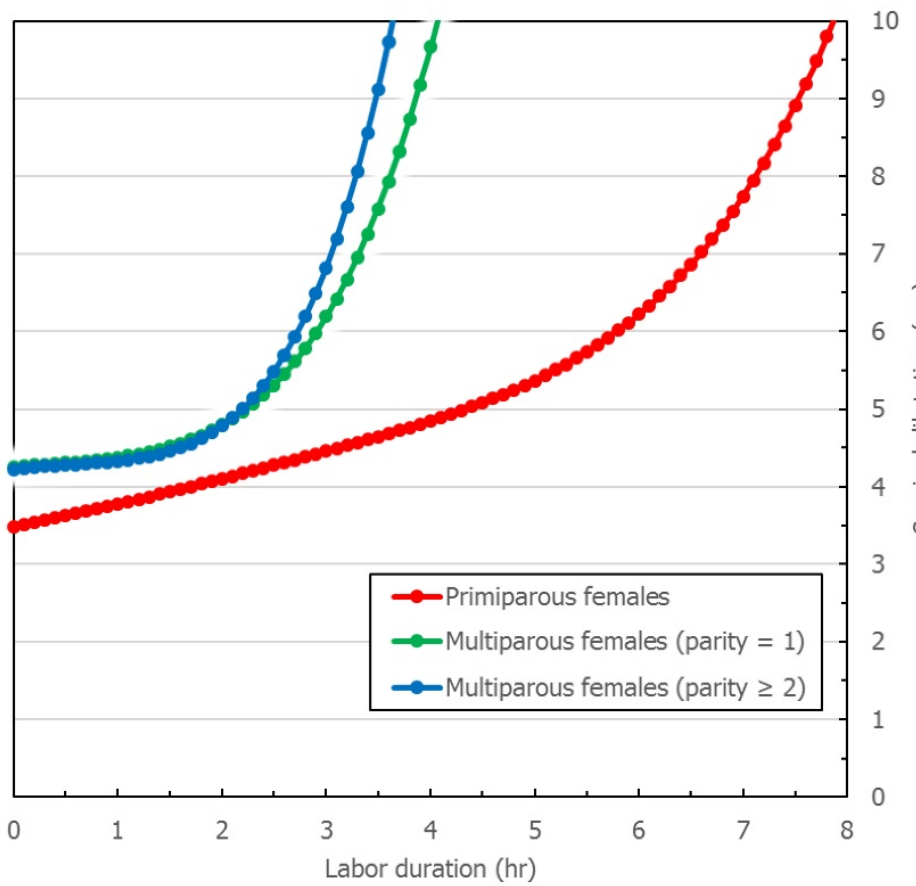

Figure 2. Cervical dilatation curves of primiparous and multiparous females. This figure describes cervical dilatation curves of spontaneous deliveries by parity with term, singleton, vertex, and live newborns of appropriate-for-gestational age birthweight without adverse perinatal outcomes.

Table 3 shows expected time intervals, by cervical dilatation stage from one centimeter to the next, in the primiparas and multiparas. Labor progressed faster with increasing parity and cervical dilatation stage. Fastest cervical changes, i.e., maximal median changes of expected time intervals between two consecutive cervical dilatation stages, occurred in $6 \mathrm{~cm}(-0.52 \mathrm{~cm} / \mathrm{hr})$ and 5 $\mathrm{cm}(-0.37 \mathrm{~cm} / \mathrm{hr}$ and $-0.33 \mathrm{~cm} / \mathrm{hr}$ for parity $=$ 1 and $\geq 2$ ) of dilatation in the primiparas and multiparas, respectively. Among the primiparas and multiparas in the $95 \%$ tile, labor progression took over 3 hours (primiparas) and over 2 hours (multiparas) to progress from $6 \mathrm{~cm}$ to $7 \mathrm{~cm}$, and from $5 \mathrm{~cm}$ to $6 \mathrm{~cm}$, respectively. All labors resulted in spontaneous deliveries without abnormal labor progression and obstetric interventions.

Table 4 shows traverse times, by cervical dilatation stage from one centimeter to the full dilatation, in the primiparas and multiparas. Labor progression developed faster with increasing parity and cervical dilatation stage (from $4 \mathrm{~cm}$ to $10 \mathrm{~cm}$, median 3.75 vs. 2.33 vs. 2.00 hours for parity $=0,1$ and $\geq 2$ ). In the active phase, the traverse times to the full dilatation 5\% tile were less than 1 hour and 0.5 hours for the primiparas and multiparas, respectively ( 0.58 hours from $6 \mathrm{~cm}$ to $10 \mathrm{~cm}$ for parity $=0 ; 0.42$ vs. 0.28 hours from $5 \mathrm{~cm}$ to 10 $\mathrm{cm}$ for parity $=1$ and $\geq 2)$. Even in the latent phase, it could be less than 1 hour $(0.77$ hours from $5 \mathrm{~cm}$ to 10 $\mathrm{cm}$ for parity $=0 ; 0.67$ vs. 0.42 hours from $4 \mathrm{~cm}$ to 10 $\mathrm{cm}$ for parity $=1$ and $\geq 2$ ).

Table 3. Expected time intervals, from one cervical dilatation stage to the next, for primiparous and multiparous females.

\begin{tabular}{|c|c|c|c|c|c|c|c|c|c|c|}
\hline \multirow{3}{*}{$\begin{array}{l}\text { Cervical } \\
\text { dilatation }(\mathrm{cm})\end{array}$} & \multirow{2}{*}{\multicolumn{3}{|c|}{ Primiparous females }} & \multicolumn{6}{|c|}{ Multiparous females } & \multirow[b]{3}{*}{ P value } \\
\hline & & & & \multicolumn{3}{|c|}{ Parity $=1$} & \multicolumn{3}{|c|}{ Parity $\geq 2$} & \\
\hline & median & $\mathrm{N}$ & $5 \%-95 \%$ tile & median & $\mathrm{N}$ & $5 \%-95 \%$ tile & median & $\mathrm{N}$ & $5 \%-95 \%$ tile & \\
\hline From 2 to 3 & $2.62^{*}$ & 168 & $1.00-8.31$ & 1.17 & 81 & $0.15-5.51$ & 1.00 & 92 & $0.11-3.24$ & $<0.0001$ \\
\hline From 3 to 4 & $2.24^{*}$ & 333 & $0.78-8.00$ & $0.87 \ddagger$ & 201 & $0.09-4.01$ & 0.83 & 237 & $0.15-4.48$ & $<0.0001$ \\
\hline From 4 to 5 & $1.83^{*}$ & 374 & $0.50-5.81$ & 0.50 & 282 & $0.09-2.25$ & 0.50 & 313 & $0.08-2.39$ & $<0.0001$ \\
\hline From 5 to 6 & $1.31^{*}$ & 351 & $0.42-4.67$ & $0.38 \ddagger$ & 292 & $0.07-2.25$ & 0.31 & 300 & $0.06-2.12$ & $<0.0001$ \\
\hline From 6 to 7 & $1.05^{*}$ & 329 & $0.33-3.13$ & 0.29 & 325 & $0.05-1.75$ & 0.25 & 307 & $0.04-1.74$ & $<0.0001$ \\
\hline From 7 to 8 & $1.00^{*}$ & 328 & $0.33-3.31$ & 0.28 & 278 & $0.04-1.67$ & 0.26 & 276 & $0.06-1.55$ & $<0.0001$ \\
\hline From 8 to 9 & $0.76^{*}$ & 476 & $0.17-2.17$ & $0.25^{\$}$ & 389 & $0.04-1.32$ & 0.19 & 383 & $0.04-1.02$ & $<0.0001$ \\
\hline From 9 to 10 & $0.52^{*}$ & 504 & $0.08-2.19$ & 0.25 & 312 & $0.07-1.16$ & 0.25 & 276 & $0.06-1.17$ & $<0.0001$ \\
\hline
\end{tabular}

${ }^{*} \mathrm{P}<0.0001$, in relation to all other groups; $\neq \mathrm{P}<0.05$, in relation to multiparous females (parity $\geq 2$ ); $\$ \mathrm{P}<0.001$, in relation to multiparous females (parity $\geq 2$ )

Table 4. Time to the full dilatation, by cervical dilatation stages, for primiparous and multiparous females.

\begin{tabular}{|c|c|c|c|c|c|c|c|c|c|c|}
\hline \multirow{3}{*}{$\begin{array}{l}\text { Cervical } \\
\text { dilatation }(\mathrm{cm})\end{array}$} & \multirow{2}{*}{\multicolumn{3}{|c|}{ Primiparous females }} & \multicolumn{6}{|c|}{ Multiparous females } & \multirow[b]{3}{*}{ P value } \\
\hline & & & & \multicolumn{3}{|c|}{ Parity $=1$} & \multicolumn{3}{|c|}{ Parity $\geq 2$} & \\
\hline & median & $\mathrm{N}$ & $5 \%-95 \%$ tile & median & $\mathrm{N}$ & $5 \%-95 \%$ tile & median & $\mathrm{N}$ & $5 \%-95 \%$ tile & \\
\hline From 2 to 10 & $6.67^{*}$ & 168 & $2.35-16.85$ & 4.12 & 81 & $1.09-10.52$ & 4.12 & 92 & $1.39-11.51$ & $<0.0001$ \\
\hline From 3 to 10 & $5.08^{*}$ & 333 & $1.33-13.54$ & $3.50 \neq$ & 201 & $0.92-8.97$ & 2.75 & 237 & $0.66-8.02$ & $<0.0001$ \\
\hline From 4 to 10 & $3.75^{*}$ & 374 & $0.89-10.21$ & 2.33 & 282 & $0.67-6.68$ & 2.00 & 313 & $0.42-6.31$ & $<0.0001$ \\
\hline From 5 to 10 & $3.00^{*}$ & 351 & $0.77-8.91$ & $1.67 \$$ & 292 & $0.42-5.25$ & 1.42 & 300 & $0.28-5.53$ & $<0.0001$ \\
\hline From 6 to 10 & $2.25^{*}$ & 329 & $0.58-6.14$ & $1.17 \$$ & 325 & $0.25-4.33$ & 0.95 & 307 & $0.17-4.03$ & $<0.0001$ \\
\hline From 7 to 10 & $1.75^{*}$ & 328 & $0.42-5.29$ & 0.75 & 278 & $0.17-3.17$ & 0.72 & 276 & $0.12-3.00$ & $<0.0001$ \\
\hline From 8 to 10 & $1.03^{*}$ & 476 & $0.17-3.18$ & $0.50 \ddagger$ & 389 & $0.08-2.08$ & 0.42 & 383 & $0.08-1.58$ & $<0.0001$ \\
\hline From 9 to 10 & $0.52^{*}$ & 504 & $0.08-2.19$ & 0.25 & 312 & $0.07-1.16$ & 0.25 & 276 & $0.06-1.17$ & $<0.0001$ \\
\hline
\end{tabular}

${ }^{*} \mathrm{P}<0.0001$, in relation to all other groups; $\mathrm{f} \mathrm{P}<0.005$, in relation to multiparous females (parity $\geq 2$ ); $\$ \mathrm{P}<0.05$, in relation to multiparous females (parity $\geq 2$ ) 
Preliminary analyses showed that labor durations increased at the second stage and did not increase at the first stage in the cases with atonic bleeding after childbirth. In Japan, the total blood loss $90 \%$ tile at singleton vaginal delivery is $800 \mathrm{~mL}$. Labor durations at the second stage between the cases with and without atonic bleeding after childbirth were as follows; median 0.95 vs. 0.70 hours for parity $=0,0.27$ vs. 0.20 hours for parity $=1$ and 0.20 vs. 0.15 hours for parity $\geq 2$. We aimed to describe averaged cervical dilatation curves in the first stage. Because atonic bleeding after childbirth is the abnormal labor progression after the third stage, these cases have been not excluded.

\section{Discussion}

We examined pregnant Japanese females without abnormal labor progression and obstetric interventions to describe cervical dilatation curves that characterized normal labor progression. Our results demonstrated that labor progression was faster with increasing parity and the active phase of labor may not start until $5 \mathrm{~cm}$ of dilatation. The results also suggested that at the beginning of the active phase, cervical dilatation was slower than previously described, and at the end of the active phase, no deceleration phase was observed. These findings may provide useful information for obstetric management, potentially reducing the need for medical intervenetions during labor.

Fastest cervical changes occurred at $6 \mathrm{~cm}$ (primiparas) and $5 \mathrm{~cm}$ (multiparas) of dilatation. These results were different from Friedman's curves with definite inflection points around $4 \mathrm{~cm}$ [2-4]. Friedman's study included many abnormal labor progression and obstetric interventions; e.g., in the primiparas, $20.8 \%$ exhibited malrotation and 51.2\% required vacuum extraction delivery [3]. Furthermore, labor curve synthesis methods were not clearly described [2-4]. Peisner and Rosen analyzed 1060 primiparas and 639 multiparas and reported that non-complicated patients with $5 \mathrm{~cm}$ of dilatation should be in the active phase [14]. This finding agrees with our data. Patients enter the active phase at different stages, and with different rates. Due to interpersonal variation, the average labor curve tends to appear flattened [6]. Consistent labor progression patterns in the active phase were not observed, particularly among the primiparas, and our labor progression was slower than those reported by Friedman [3, 4]. Zhang et al. analyzed 62415 deliveries, from 2002 to 2008, and reported that primiparas and multiparas seemed to progress at a similar pace, before $6 \mathrm{~cm}$, and cervical dilatation rate accelerated after $6 \mathrm{~cm}$ [5]. Another study of 26838 deliveries, from 1959 to 1966, revealed that multiparas consistently seemed to progress at a faster pace than primiparas [15]. Demographic transition might affect labor progression and duration [3, 4, 8-13]. Epidural analgesia and weak pains during oxytocin use may lengthen the active phase [2-4, 12]. Because Zhang's study included a substantial number of participants with oxytocin use and epidural analgesia [5], their labor progression developed more gradually than our labor progression.

The 95\% tile of labor progression took over 3 hours to progress from $6 \mathrm{~cm}$ to $7 \mathrm{~cm}$ (primiparas), and over 2 hours to progress from $5 \mathrm{~cm}$ to $6 \mathrm{~cm}$ of dilatation (multiparas). Considering labor augmentation in the active phase, cervical dilatation of $\leq 1.2$ $\mathrm{cm} / \mathrm{hr}$ and $\leq 1.5 \mathrm{~cm} / \mathrm{hr}$ for primiparas and multiparas were defined as protracted disorders of labor [3, 4]. Previously in Japan, 2-hour and 1-hour thresholds were usually used for diagnosing arrested disorders of labor, for primiparas and multiparas, after $4 \mathrm{~cm}$, which was considered as "in the active phase" in Friedman's curves $[3,4]$. These criteria may be too short before $6 \mathrm{~cm}$ [15], considered as "in the latent phase" in present curves $[6,7]$. Our participants achieved spontaneous deliveries even if their labor durations exceeded the $95 \%$ tile of expected time intervals, which exceeded those thresholds. Diagnosis of protracted or arrested labor should be based, not only on research definitions, but also on maternal and fetal conditions [5]. Offering reassurance of maternal and fetal statuses, within a normal labor duration range, may allow patients to continue spontaneous labor progression. To optimize the opportunities for appropriate management of labor and improve perinatal prognoses, prospective studies are needed to establish clinical thresholds for diagnosing protracted or arrested labor. The upper limit of the normal range, i.e., the $95 \%$ tiles of expected durations, may be the useful reference for these types of prospective studies.

The $5 \%$ tile of traverse times to the full dilatation, during the active phase, was less than 1 hour (primiparas) and 0.5 hours (multiparas). Natural history of the normal active phase, during the first stage of labor, predicted labor progression. Recent reports of labor curve creation [6, 7] included inclusion criteria of cervical dilatation $<7 \mathrm{~cm}$ at admission and labor duration, from admission to delivery, of $>3$ hours. Based on these criteria, most precipitate labors could be excluded. Sheiner et al. observed no significant differences in perinatal complications, but higher rates of maternal complications, associated with precipitate labor [16]. 
During precipitate labor progression, newborns may fall onto hard surfaces, or suffer unexpected injuries without the benefit of delivery assistance. Intense contractions may cause other perinatal complications. In our study, the prevalence of precipitate labor was $21.3 \%(4.4 \%$ vs. $29.6 \%$ for parity $=0$ and $\geq 1)$, which was higher than $14.3 \%(6.9 \%$ vs. $21.5 \%$ for parity $=0$ and $\geq 1$ ) reported from a prior Japanese study [17]. These prevalence rates were markedly higher than $2.1 \%$, reported in a study out of the United States [18]. As mentioned above, in Japan, onset of labor is defined as the presence of regular contractions separated by $\leq 10$ minutes, as reported by the patient. Suzuki noted that the high incidence of precipitate labor may result from differing definitions, or from diagnosis of regular contractions by clinical monitoring devices, and not the patient's declaration [17].

No deceleration phase was observed at the end of the active phase. Friedman noted that it maintains maximum dilatation rate until $8 \mathrm{~cm}$ to $9 \mathrm{~cm}$ of dilatation and the dilatation rate appears to slow down, but acknowledged, "In actually, normally nothing slows." [19] We rarely observed the deceleration phase in the majority of participants, nor had been observed in previous studies [6, 7]. Deceleration phase marks the time in labor when the process of fetal descent becomes maximized, and is often short or absent, probably because it is merely not being observed $[6,19]$. However, Friedman's labor curves included $25.6 \%$ of primiparas and $6.4 \%$ of multiparas, with the deceleration phase longer than 1 hour and 0.5 hours, respectively [3, 4]. Labor curve associated with prolonged deceleration phase due to dystocia has a prolonged active phase and low maximum slope [3], which will significantly affect the mean labor curve. Lack of the deceleration phase in the present study may be caused by excluding cases with dystocia.

Maternal and neonatal characteristics have clearly changed over the past 60 years, and this can affect labor progression patterns. Average maternal age is rising, and the first stage of labor progresses more quickly with increasing maternal age [8]. Average maternal body mass is also increasing, and the first stage of labor progresses more slowly in patients with BMIs of 30 or more [9]. According to the Ministry of Health, Labour and Welfare, maternal characteristics in the present study were not different from those of the averaged Japanese females. For instance, in 2015, average maternal age at delivery of primiparas and multiparas (parity $=1$ and $\geq 2$ ) were $30.7,32.5$ and 33.5, respectively [20]. We also observed that labor progressed quickly with increasing maternal age, and slowly with increasing maternal body mass (not shown). Mean maternal age of primiparous patients was 30 and over, associated with advancing late birth. Overweight females are less common, and lean females are more common, in Japan. Considering these tendencies, new clinical references for appropriate management of labor progression are needed.

This study had a number of limitations. First, we did not determine the reliability of intrapersonal and interpersonal cervical dilatation measurement, and prospective, hourly vaginal examinations were not performed, as described by Friedman [2-4]. Second, because constructions were assessed by the attending obstetricians and midwives, the reliability of intrapersonal and interpersonal labor diagnosis was not assessed. Third, we acknowledge that selection bias, related to the exclusion criteria, might underestimate the normal ranges, i.e., the $5 \%$ tile and $95 \%$ tile of various measurements. Finally, the current database likely reflects a comparatively urban Japanese population. However, we believe that our results accurately depict the cervical dilatation curves, of spontaneous deliveries in pregnant Japanese females. These curves provide useful information for obstetric management and may reduce the need for obstetric interventions during labor progression.

\section{Acknowledgements}

We thank Dr. Saburo Kogi, Dr. Yong-soon Kim, Dr. Norihiro Matsushita and Dr. Hideki Iwamoto (Berun Forest Clinic and Belier Hill Clinic), Dr. Hiroshi Ohmura (Ladies Clinic Concerto), Dr. Toshimasa Machida (Machida Obstetrics and Gynecology Nanohana Clinic), Dr. Masako Juzoji (Higashi-Fuchu Hospital), Dr. Satoru Yamaguchi (Yamaguchi Women's Hospital), and Ms. Mizue Hagiwara (Nippon Medical School Tama-Nagayama Hospital) for their patience in medical record preparation.

\section{Competing Interests}

The authors have declared that no competing interest exists.

\section{References}

1. Spong CY, Berghella V, Wenstrom KD, et al. Preventing the first cesarean delivery: summary of a Joint Eunice Kennedy Shriver National Institute of Child Health and Human Development, Society for Maternal-Fetal Medicine, and American College of Obstetricians and Gynecologists Workshop. Obstet Gynecol. 2012; 120: 1181-93.

2. Friedman EA. The graphic analysis of labor. Obstet Gynecol. 1954; 68: 1568-75.

3. Friedman EA. Primigravid labor; a graphicostatistical analysis. Obstet Gynecol. 1955; 6: 567-89.

4. Friedman EA. Labor in multiparas; a graphicostatistical analysis. Obstet Gynecol. 1956; 8: 691-703.

5. Zhang J, Landy HJ, Branch DW, et al. Consortium on Safe Labor. Contemporary patterns of spontaneous labor with normal neonatal outcomes. Obstet Gynecol. 2010; 116: 1281-7.

6. Zhang J, Troendle JF, Yancey MK. Reassessing the labor curve in primiparous women. Am J Obstet Gynecol. 2002; 187: 824-8. 
7. Suzuki R, Horiuchi S, Ohtsu H. Evaluation of the labor curve in primiparous Japanese women. Am J Obstet Gynecol. 2010; 203: 226.e1-6.

8. Zaki MN, Hibbard JU, Kiminiarek MA. Contemporary labor patterns and maternal age. Obstet Gynecol. Obstet Gynecol. 2013; 122: 1018-24.

9. Norman SM, Tuuli MG, Odibo AO, et al. The effects of obesity on the first stage of labor. Obstet Gynecol. 2012; 120: 130-5.

10. Feghali M, Timofeev J, Huang CC, et al. Preterm induction of labor: predictors of vaginal delivery and labor curves. Am J Obstet Gynecol. 2015; 212: 91.e1-7.

11. Leftwich HK, Zaki MN, Wilkins I, et al. Labor patterns in twin gestations. Am J Obstet Gynecol. 2013; 209: 254.e1-5.

12. Alexander JM, Sharma SK, McIntire DD, et al. Epidural analgesia lengthens the Friedman active phase of labor. Obstet Gynecol. 2002; 100: 46-50.

13. Timofeev J, Huang CC, Singh J, et al. Spontaneous labor curves in women with pregnancies complicated by diabetes. J Matern Fetal Neonatal Med. 2012; 25: 20-6.

14. Peisner DB, Rosen MG. Transition from latent to active labor. Obstet Gynecol. 1986; 68: 448-51.

15. Zhang J, Troendle J, Mikolajczyk R, et al. The natural history of the normal first stage of labor. Obstet Gynecol. 2010; 115: 705-10.

16. Sheiner E, Levy A, Mazor M. Precipitate labor: higher rates of maternal complications. Eur J Obstet Gynecol Reprod Biol. 2004; 116: 43-7.

17. Suzuki S. Clinical significance of precipitous labor. J Clin Med Res. 2015; 7: 150-3.

18. Martin JA, Hamilton BE, Sutton PD, et al. Births: final data for 2006. Natl Vital Stat Rep. 2009; 57: 1-102.

19. Friedman EA. The labor curve. Clin Perinatol. 1981; 8: 15-25.

20. [Internet] Ministry of Health, Labour and Welfare: Tokyo, Japan. Vital statistics in Japan: Trends up to 2015. Published March 2017. http://www. mhlw.go.jp/toukei/list/dl/81-1a2.pdf 